\section{OBJETIVO: GARCÍA LORCA. NUEVAS INQUISICIONES CINEMATOGRÁFICAS Y TELEVISIVAS SOBRE LA VIDA, OBRA Y MUERTE DEL POETA}

\author{
Jorge Marí \\ North Carolina State University \\ jmari@unity.ncsu.edu
}

\begin{abstract}
This essay, "Objetivo: García Lorca. Nuevas inquisiciones cinematográficas y televisivas sobre la vida, obra y muerte del poeta", explores several representations of Federico García Lorca in Spanish film and TV productions of recent decades. The focus on the figure of the author rather than on the adaptations of his plays favors the analysis of the representation of two, closely intertwined processes: that of literary creation-how the creative process is portrayed, and how the artist's life is seen to intertwine with his work-and that of the cultural construction of the artist, in retrospect, as a historic figure and a cultural icon. This seems a particularly appropriate perspective in the case of García Lorca, whose fame and cultural significance owe as much to the circumstances of his life and death as they do to his plays and poems, and who in recent decades has been vindicated, reinvented, and re-introduced as an emblematic presence and a foundational myth of a contemporary, autonomous Andalucia and a democratic Spain. The article traces all those processes through recent documentaries such as Emilio Ruiz Barrachina's Lorca, el mar deja de moverse, Magali Negroni's F.G.L. (1898-1936): Federico cumple 100 años and Basilio Martín Patino's "mockumentary" El jardín de los poetas.
\end{abstract}

KEY WORDS: Federico García Lorca; documentary; mockumentary; Basilio Martín Patino; Spanish Civil War; memory; Spanish television; Andalucian television; Spanish cinema.
TARGET: GARCÍA LORCA. NEW CINEMATOGRAPHIC AND TELEVISION INQUISITIONS ON POET'S LIFE, WORK AND DEATH

RESUMEN: Este ensayo explora algunas representaciones de la figura de Federico García Lorca en la televisión y el cine españoles de las últimas décadas. El énfasis en la representación de la figura de García Lorca más que en las adaptaciones de sus obras dramáticas favorece el análisis de dos cuestiones intimamente conectadas entre sí: en primer lugar, la representación mediático-audiovisual del proceso de creación literaria y de la interacción de autor y texto -es decir, cómo se construye la figura del escritor como ente creador, cómo se entiende dicho proceso de creación, y muy especialmente cómo se presenta la relación e influencia mutuas entre la vida y la obra del artista- y en segundo lugar, la construcción, realizada desde la distancia temporal y desde un contexto muy diverso al de su propia vida, de la figura del artista como personaje histórico y mito cultural. Este enfoque parece especialmente apropiado al tratarse de un autor que, por su vida y su muerte tanto o más que por su obra, ha pasado de ser un proscrito bajo el primer franquismo a convertirse en una figura emblemática de la Andalucía autonómica y de la España democrática. El ensayo traza este proceso de recuperación, reinvención, reivindicación y debate sobre García Lorca a través de documentales como Lorca, el mar deja de moverse de Emilio Ruiz Barrachina, F.G.L. (1898-1936): Federico cumple 100 años de Magali Negroni y del "documental de ficción" El jardín de los poetas de Basilio Martín Patino.

PALABRAS CLAVE: Federico García Lorca; documental; documental de ficción; Basilio Martín Patino; guerra civil española; memoria; televisión (española y andaluza); cine español. 
"Dicen que el cine es el arte de que sucedan las cosas que no suceden, para que así podamos pensarlas como si existieran. La televisión en cambio consistiría en presentar como bellas mentiras lo que si ha podido existir"

(El jardín de los poetas, de Basilio Martín Patino).

En el considerable corpus crítico sobre las relaciones entre Federico García Lorca y el cine ocupan un lugar prominente, numéricamente hablando, los estudios dedicados a la influencia del cine en la formación estética y sentimental del poeta granadino, las manifestaciones explícitas o implícitas del lenguaje y universo cinematográficos en los textos lorquianos, y las adaptaciones cinematográficas de sus obras dramáticas ${ }^{1}$. Frente a estas líneas de investigación establecidas, el presente ensayo propone un análisis de las representaciones de la figura de García Lorca en algunos documentales televisivos y cinematográficos españoles de los últimos años. El enfoque en la representación de la figura de García Lorca, más que en las adaptaciones de sus obras dramáticas, favorece el análisis de dos cuestiones intimamente conectadas entre sí: en primer lugar, la representación mediático-audiovisual del proceso de creación literaria y de la interacción de autor y texto -es decir, cómo se construye la figura del escritor como ente creador, cómo se entiende dicho proceso de creación, y muy especialmente cómo se presenta la relación e influencia mutuas entre la vida y la obra del artista- y en segundo lugar, la construcción, realizada desde la distancia temporal y desde un contexto muy diverso al de su propia vida, de la figura del artista como personaje histórico y mito cultural. Las preocupaciones culturales, históricas e ideológicas de este estudio parecen particularmente relevantes al tratarse de un autor cuya vida (y sobre todo, muerte) ha despertado tanto o más interés crítico que su propia obra y que, de proscrito bajo el primer franquismo e icono de la izquierda desde los mismos tiempos de la guerra civil, ha pasado a ser reivindicado y reinventado como emblema de la España democrática y mito fundacional de la Andalucía autonómica de hoy. Se trata, pues, de insertar el estudio de las representaciones mediáticas de García Lorca en el debate sobre las conceptualizaciones y prácticas de la historia y la memoria colectiva; de afrontar el pasado como representación, como una construcción discursiva y performativa que se ha utilizado a su vez para construir las identidades colectivas del presente.

Iniciados ya durante el tardofranquismo y acentuados a lo largo de la transición, los procesos de recuperación, reinvención, reivindicación y debate mediático sobre García Lorca experimentan un auge inusitado en torno a las celebraciones del 50 aniversario de su muerte en 1986 y, de forma todavía más notable, a partir de los años inmediatamente precedentes a 1998, con ocasión del centenario de su nacimiento, manteniéndose hasta hoy en toda su intensidad. Así, a tempranos documentales televisivos españoles y europeos como Zorongo (Recordando a García Lorca), de Eugenio Pena (1969), Deep Song, Black Sound (documental de la BBC de 1968), La Granada de García Lorca (episodio de la serie de TVE La víspera de nuestro tiempo dirigido por Jesús Fernández Santos en 1968), Assassinio de Federico García Lorca y Federico García Lorca: Murder in Granada -mini-series de televisión italiana y sueca, respectivamente (1976)- así como el largometraje $A$ un dios desconocido, de Jaime Chávarri (1977), se añaden a mediados de los 80 El balcón abierto, de Jaime Camino (1984), la serie de televisión Lorca, muerte de un poeta, dirigida por Juan Antonio Bardem (1986, también estrenada en versión largometraje en 1987) y, a partir de mediados de los 90, un auténtico boom que incluye, entre otros, el "documental de ficción" El jardín de los poetas (Basilio Martín Patino, 1995), el largometraje estadounidense Muerte en Granada (Marcos Zurinaga, 1997), la serie de cuatro documentales de Canal + Televisión Lorca, centenario de un poeta (1998), el documental F.G.L. (1898-1936): Federico cumple 100 años, de Magali Negroni (1998), Federico García Lorca: retrato de familia (documen- 
tal de TVE dirigido por Enrique Nicanor en 1998), la serie de Canal Sur TV Buscando a Lorca (1998), Lorca, Santiago y seis poemas gallegos (Alber Ponte,1999), el largometraje La luz prodigiosa de Miguel Hermoso (2003), Lorca, el mar deja de moverse (documental producido por la Radiotelevisión Valenciana y dirigido por Emilio Ruiz Barrachina en 2006), y Little Ashes, largometraje del británico Paul Morrison cuyo estreno está previsto para 2009. Todo ello sin contar con las abundantes adaptaciones televisivas y cinematográficas de sus obras dramáticas, demasiado numerosas para consignarlas aqui ${ }^{2}$.

Esta abrumadora recurrencia de producciones sobre la figura de García Lorca en las últimas décadas debe estudiarse en íntima conexión con el contexto histórico y cultural del posfranquismo, que incluye el desarrollo del sistema democrático y del estado de las autonomías y el consiguiente establecimiento de instituciones y promoción de nuevas identidades colectivas; y como elemento inherente al contexto transicional y post-transicional, hay que considerar la incómoda, pertinaz e ineludible presencia del pasado y las estrategias que, desde dentro y fuera de las instituciones, se han desplegado para tratar con el mismo: silencio, olvido, amnesia y "desmemoria", reivindicación, reinvención, celebración, nostalgia y conmemoración, entre otras. Por la relevancia de su obra y por las circunstancias de su vida -y muy especialmente, de su muerte- la figura de García Lorca ha servido, y sigue sirviendo, como referencia y como un señalado lugar de memoria en relación con la cuestión de las víctimas del franquismo, la posibilidad de justicia, reconciliación, sutura y superación definitiva de las heridas de la guerra y la posguerra.

Teniendo en cuenta lo anterior, parece apropiado traer a colación el texto del Estatuto de Autonomía de Andalucía, cuya aprobación en referéndum en febrero de 2007 supone la culminación de un proceso de reformas, puntualizaciones y adiciones gestadas a lo largo de los años que lo separan del texto precedente de 1981. El Estatuto es relevante no sólo porque establece el marco legal e ideológico desde el que se ha venido construyendo y dirigiendo institucionalmente la formación de una identidad colectiva andaluza a lo largo del posfranquismo, sino también porque tanto las celebraciones del 50 aniversario de la muerte de García Lorca como, muy especialmente, las del primer centenario de su nacimiento han sido en gran medida fomentadas, organizadas y/o subvencionadas por las instituciones autonómicas y estatales, y por lo tanto no pueden entenderse al margen de las conceptualizaciones y prácticas de la "andalucidad" -ni de la "españolidad" que le sirve de marco y referencia- promovidas por dichas instituciones.

El Preámbulo del Estatuto proclama que Andalucía es una "nacionalidad", rescatando la expresión "realidad nacional" del Manifiesto Andalucista de Córdoba de 1919 y exaltando su "robusta y sólida identidad" y su "carácter singular", a la vez que puntualiza que el patrimonio social y cultural andaluz es "parte esencial de España". Tanto la condición nacional de Andalucía como su españolidad se reiteran en el Artículo Primero, que define a Andalucía como una "nacionalidad histórica" constitutida "en el marco de la unidad de la nación española". En cuanto a esto último, el Preámbulo hace mención explícita al Artículo Segundo de la Constitución, que establece la "indisoluble unidad de la Nación española". Ahora bien, el texto no define ninguno de los términos clave -nacionalidad, nación, ni mucho menos "realidad" ni "esencia"- ni explica en qué consiste la identidad andaluza, ni qué le confiere su "carácter singular". En cambio, se reiteran enfáticamente el "mestizaje", la "multiplicidad", "interculturalidad", "pluralidad" y "diversidad" andaluzas, y se declara que la "personalidad andaluza" -otro concepto problemático que tampoco se define- está construida "sobre valores universales". Paradójicamente, esa incontestable identidad andaluza en la que, según el Estatuto, se fundamentan la reivindicación nacional y el carácter único de Andalucía como pueblo, no parece poder explicarse sino en base a su universalidad, diversidad e interculturalidad, ni parece tener sentido sino dentro de una supranación-estado a la que se le reconoce su "unidad indisoluble".

No debe sorprender que la condición paradójica y esquizoide de una "andalucidad" planteada de forma tan ambivalente se plasme en los discursos institucionales que afectan a la construcción de la memoria cultural. En su análisis de la conmemoración del Centenario del nacimiento de García Lorca en 1998, Stefan Schreckenberg señala que uno de los debates centrales de los actos conmemorativos fue precisamente el que enfrentaba a los defensores del "andalucismo" de García Lorca (así como los que lo reivindicaban por encima de todo como autor gay o como activista de izquierdas) y los que lo ensalzaban como "poeta universal". Dicho debate puede trazarse 
al comparar unos documentales con otros, e incluso al analizar individualmente algunos de ellos. Federico García Lorca: retrato de familia -producción de TVE que, según Schreckenberg, constituye el documental oficial del Centenario- es uno de los que pone mayor énfasis en la universalidad de García Lorca; una universalidad que, significativamente, se identifica con los Estados Unidos: abundan las imágenes de Nueva York, se dedica gran atención a la estancia del poeta en la ciudad y a los textos de Poeta en Nueva York, se recogen comentarios de autores estadounidenses, y el análisis principal corre a cargo de un crítico de dicho país, Christopher Maurer. Como indica Schreckenberg, "Nueva York aparece como la capital de un mundo moderno y cosmopolita, es más, el juicio entusiasta de los escritores americanos sobre Lorca contribuye a presentarlo como un autor moderno consagrado" (229). No se le escapa a Schreckenberg otra dimensión de esta particular "universalización" de García Lorca cuando comenta que un objetivo de Federico García Lorca: retrato de familia es precisamente "aumentar la notoriedad de un autor español en Estados Unidos" (229), país en el que la familia del poeta -participante activa en el documental a través de la Fundación que lleva su nombre- tiene gran arraigo. Estos elementos son consistentes con uno de los objetivos centrales del Centenario, que Schreckenberg define como "presentar a García Lorca en el extranjero como destacado representante de la cultura española y como escritor de importancia mundial", tarea en la que se vuelcan entes estatales como TVE y el Instituto Cervantes (Schreckenberg, 2006, 225-26). En esa línea se sitúan las declaraciones de Maurer en Federico García Lorca: retrato de familia -"[García Lorca] no pertenece a Andalucía; crea una imagen de Andalucía pero no pertenece a los andaluces ni a los españoles"- y las de Manuel Fernández-Montesinos, director de la Fundación Federico García Lorca y sobrino del poeta, cuando en diversos foros define a éste como "ciudadano del mundo", reitera que "el Lorca 'universal' es el único aceptable" y declara que "[v]er a García Lorca como andalucista es agarrarse a lo anecdótico" (cit. por Schreckenberg, 2006, 232-35). Sin embargo, donde la cuestión del andalucismo de García Lorca, y más específicamente, la construcción mediática de la figura del poeta desde una cierta perspectiva institucional andaluza, se somete a una disección más punzante es sin duda en El jardín de los poetas, "documental de ficción" de Basilio Martín Patino al que este ensayo dedicará atención aparte más adelante ${ }^{3}$.
Aunque comprensible por los intereses políticos y comerciales que lo impulsan, la fiereza del debate mediático entre los proponentes de la "andalucidad", "españolidad" y "universalidad" de García Lorca no hace sino agudizar la ironía de que tal debate se construye sobre una paradoja: si la identidad andaluza está fundamentada, según el Estatuto, en su pluralidad, diversidad, multiculturalidad y mestizaje y en la defensa de valores universales, entonces no solamente no existe incompatibilidad entre "andalucidad" y "universalidad" sino que aquélla es un índice de ésta: cuanto más "andaluz", más "universal" será un autor, una obra, un producto cultural. Resulta interesante que una argumentación lógica tan elemental haya conseguido pasar casi desapercibida en tantos años de empecinado debate.

Más allá de su falta de sustancia o de su incoherencia, lo que subyace a este debate es el interés por parte de instituciones, tanto autonómicas como estatales, así como de sectores políticos y sociales, de construir y consolidar a García Lorca como mito fundacional, emblema cultural y símbolo de identidad, lo cual a menudo ha conllevado la descalificación o el desprestigio de los mitos ajenos. Dichos esfuerzos, por su parte, han estado en permanente enfrentamiento con los intentos de desmitificación de la figura del poeta, los cuales, a su vez, han sido en ocasiones intentos de "remitificación" bajo otros parámetros. De hecho, la historia de las diversas mitificaciones, desmitificaciones y "remitificaciones" de García Lorca a través de las décadas no es sino la historia del franquismo, la transición y la democracia. Con ocasión de la entrega del Premio Espejo de España a José Luis Vila-San Juan por su libro García Lorca, asesinado: toda la verdad -afín a la línea de despolitización de la figura de García Lorca largamente defendida por el régimen-, Fraga Iribarne afirmaba en 1975 que "había que descubrirle de una vez [a García Lorca] para enterrarle de una vez" (Dinverno, 2005, 43). En el mismo sentido, aunque en otro contexto políticocultural y desde una perspectiva ideológica en principio diferente, el periodista A. Víctor García proclamaba en $E l$ País en 1986, con ocasión de los actos conmemorativos del 50 aniversario de la muerte de Lorca, que "[e]l año dedicado a García Lorca nace para desmitificar la vida y la obra del poeta... como bandería política de la izquierda y como inspirador de ripios folclóricos para los vates de la derecha". A la "amalgama contradictoria" construida por unos y por otros, continúa García, "ha de sobreponérsele la 
imagen del Lorca vitalista, creador y difusor de la cultura". Se trata, pues, de un proyecto de descalificación de ciertas mitologías y de su sustitución por otras, objetivo para el que el entonces alcalde de Granada, Antonio Jara, imponía un esfuerzo planificado y coordinado al decretar que "se debe evitar que cada localidad o institución organice sus actos peculiares", debiéndose encuadrar todos ellos "en un homenaje único" bajo los auspicios de instituciones españolas e internacionales como el Consejo de Europa o la Unesco. 50 años después de su muerte, concluye el artículo de García, "se quiere traer una imagen distinta, sin más apasionamiento que el literario... sin auras de desidia o falso lirismo" (García, "El año dedicado a Federico García Lorca"). Retrospectivamente, a la luz de la incesante producción cultural y la imparable mitificación de la figura de García Lorca en las últimas décadas, proclamas tan ostensiblemente desmitificadoras como las de Fraga en 1975 y la del periodista de El País y del alcalde de Granada una década después deben verse con una cierta ironía. El mismo diario El País reconoce implícitamente la irremisible condición mítica de García Lorca cuando, otra década más tarde, califica la conmemoración de su Centenario nada menos que como el "año santo" del poeta (Schreckenberg, 2006: 224).

Se ha reiterado hasta la saciedad que el factor pivotal en los procesos de mitificación de Garcia Lorca ha sido, y sigue siendo, su muerte. El análisis de las producciones televisivas y cinematográficas, documentales y de ficción, que se han acercado a la figura del poeta desde la transición hasta hoy demuestra la validez de esta aserción en un grado equiparable, si no superior, al que se manifiesta en los textos históricos, en la crítica literaria, y en la prensa escrita. No es solamente el hecho de que García Lorca fuera asesinado, ni las terribles circunstancias de su asesinato, lo que fundamenta la mitificación, creciente con el paso de las décadas, de la muerte de García Lorca. Como ha observado Melissa Dinverno en dos ensayos de importancia capital, el hecho de que su cadáver no haya sido recuperado ni identificado lo convierte en un símbolo de la herida abierta de la guerra; la ausencia de su cuerpo, o por decirlo de otro modo, su cuerpo ausente, es lo que mantiene viva y vigente la figura de García Lorca como una presencia espectral del pasado en el presente, como un espacio para la reescritura de dicho pasado, para la creación de historias múltiples y contradictorias (Dinverno, 2007, 6). En "Raising the Dead: Garcia Lorca,
Trauma and the Cultural Mediation of Mourning", Dinverno muestra cómo la fetichización de la muerte de García Lorca se corresponde con el papel icónico del poeta como mediador de un luto colectivo e individual todavía por resolver (32). El mismo artículo se hace eco de un proceso, ya apuntado por otros críticos como Paul Julian Smith o Luis Fernández Cifuentes, de "somatización" de la obra y "textualización" del cuerpo de García Lorca, es decir, una confluencia entre la vida/muerte y la obra, entre el corpus literario y el cuerpo -ausente, fantasmal-del autor. Constata Dinverno cómo a través de este proceso se han llegado a consolidar lecturas y valoraciones críticas en las que vida/muerte y obra se han hecho inseparables y hasta indistinguibles. Para lan Gibson, por ejemplo, la obra de Garcia Lorca es importante en la medida en que materializa la persona de García Lorca (Dinverno, 2005, 44); Miguel García Posada ensalza "la obra del poeta que encarnó, con su vida y su obra, el destino trágico de una España en trance de matarse a sí misma" (Dinverno, 2005, 45).

La confluencia de vida, muerte y producción literaria, el simbolismo cultural e histórico y la significación política de su asesinato, el papel de la muerte en los textos lorquianos, e incluso un supuesto sentido premonitorio del poeta acerca de su propia muerte son elementos que aparecen destacada y reiteradamente en las producciones televisivas y cinematográficas sobre García Lorca en las últimas décadas. Ya los títulos son de por sí bastante significativos: Assassinio di Federico García Lorca; Federico García Lorca: Murder in Granada; Muerte en Granada (The Disappearance of García Lorca); Lorca, muerte de un poeta; El balcón abierto; Lorca: El mar deja de moverse ${ }^{4}$. Federico García Lorca: Retrato de familia se inicia con el ruido de disparos e incluye imágenes de una tumba; Así que pasen cien años -de la serie de documentales producidos por Canal + Televisión en 1998- "escenifica", en palabras de Schreckenberg, "el fantasma de un lugar de culto... con imágenes nebulosas de un camino nocturno que nos lleva a un lugar que bien podría ser su tumba" (233); Lorca, muerte de un poeta, de Bardem, comienza con la secuencia del asesinato, que se retoma al final; también El balcón abierto de Jaime Camino escenifica la muerte del poeta ${ }^{5}$. En otros dos documentales, Lorca: El mar deja de moverse y F.G.L. (1898-1936): Federico cumple 100 años, la muerte se presenta en una diversidad de niveles y provoca algunas reflexiones que merecen tratamiento aparte.

ARBOR Vol. 187748 marzo-abril [2011] 211-222 ISSN: 0210-1963 
La carátula del DVD presenta a Lorca: El mar deja de moverse como "la gran revelación sobre la muerte de Lorca", lema que no deja de evocar el título del libro de Vila-San Juan, García Lorca, asesinado: toda la verdad, mencionado en otra parte de este ensayo. Tanto el título de dicho libro como el epígrafe del documental de Ruiz Barrachina esgrimen términos dotados de una dimensión sensacionalista -"asesinato" y "muerte", respectivamente- en conjunción con el apellido del poeta, conjunción que ha sido explotada en otros libros -siendo The Assassination of Federico García Lorca (El asesinato de García Lorca) de lan Gibson el ejemplo más notable- y en una cantidad abrumadora de películas y series de televisión como las que se han mencionado más arriba. Al mismo tiempo, también como en el título de Vila-San Juan, el epígrafe de este documental promete, o al menos sugiere, un "cierre", una respuesta definitiva a los enigmas sobre la muerte de García Lorca, y consiguientemente, él mismo se promete como el documental "definitivo". En realidad, Lorca: El mar deja de moverse aporta solamente revelaciones menores, como ciertos datos sobre los roces entre las familias Roldán y Alba y la familia García, y la consiguiente creación de una animosidad hacia el padre de Federico que se hizo extensiva a éste.

El documental arranca con un fragmento de "Asesinato", de Poeta en Nueva York, que da la clave del título de la película. Este inicio cumple varias funciones: por una parte, contribuye a marcar desde el principio el tono trágico y el protagonismo de la muerte anunciado en la misma portada del DVD; al mismo tiempo, introduce el argumento, en el que se insistirá durante todo el documental, de que García Lorca tuvo desde época temprana una conciencia premonitoria de su propia muerte violenta y que dicha conciencia se transparenta a lo largo de su obra; en tercer lugar, y por efecto de lo anterior, este inicio apunta a la tarea de "somatización" de la obra y "textualización" del cuerpo lorquianos que se ha mencionado más arriba y que habrá de manifestarse plenamente en el documental de Ruiz Barrachina.

A lo largo de Lorca: El mar deja de moverse se van intercalando imágenes del proceso de creación de un retrato de García Lorca encargado para la ocasión. Una voz en off informa de que "solicitamos al pintor Luis Torroba un retrato de Federico que conjugase en su mirada el terror de la muerte y la fortaleza de su poesía". El comentario es interesante porque expresa la existencia de una visión preestablecida sobre el poeta, un retrato mental e ideológico predeterminado al que el retrato pictórico debe ajustarse, subrayando así el modo en que el propio documental de Ruiz Barrachina viene, a su vez, a corroborar un mito ya establecido. Se impone, pues, un retrato pictórico y mediático del poeta cuya vida y obra aparecen imbricadas y marcadas teleológicamente por su muerte trágica. Este planteamiento se reitera a lo largo del documental, apoyado sobre todo por las frecuentes declaraciones intercaladas del escritor Félix Grande. "Toda la poesía de Federico parece que está escrita de noche", afirma Grande para ilustrar la idea de que García Lorca poseía un don premonitorio acerca de su propia muerte. Tras referirse al poema "Sueño" ("Mi corazón reposa junto a la fuente fría...")6, Grande identifica la "fuente fría" como la Fuente de las Lágrimas, en Alfacar, muy cerca del lugar donde se cree que fue asesinado y enterrado el poeta, y concluye que García Lorca "se adelantó a la historia, fue señalando cómo tenían que enterrarlo para que no apareciera". La voz en off contribuye, a su vez, a fortalecer la lectura teleológica de la vida del poeta con frases como "el destino había comenzado a tejer el drama de su muerte muchos años atrás..." que sirven para entrelazar las distintas fases del relato y van dotando a la obra y la vida de García Lorca, retrospectivamente, de una cohesión y un sentido de inevitabilidad. El aura trágica en torno a su figura se ve reforzada por la evocación, tan gráfica como especulativa, que hace Grande de los últimos instantes de la vida del poeta. Mediante estos y otros recursos, Lorca: El mar deja de moverse apuntala una imagen de García Lorca como héroe trágico y mito cultural, imagen confeccionada a partir de un molde preestablecido al que, como el retrato del pintor Torroba, se ajusta detalladamente.

El documental F.G.L. (1898-1936): Federico cumple 100 años conjuga en su título un elemento de muerte -las iniciales del autor seguidas de las fechas de nacimiento y de muerte, que evocan la inscripción de una lápida- con una proclamación de pervivencia, una celebración de la vigencia continuada de la figura de García Lorca y de su obra -el "cumpleaños" al que alude la segunda parte del título-. Significativamente, es el primer elemento -la muerte- el que adquiere protagonismo destacado desde el inicio del documental, el cual muestra imágenes de fusilamientos sobre una voz en off que declama un fragmento de Bodas de sangre: precisamente el lamento de la 
madre al final de la obra, que en este caso evoca el de la propia madre de García Lorca tras el asesinato de su hijo, 0 , de forma más simbólica, el lamento colectivo ante la tragedia de la guerra civil: "Ya todos están muertos. A medianoche dormiré, dormiré sin que ya me aterren las escopetas o el cuchillo. Otras madres se asomarán a las ventanas... para ver el rostro de sus hijos. Yo no. Yo haré con mi sueño una fría paloma de marfil que lleve camelias de escarcha sobre el camposanto". Este tipo de montaje de textos e imágenes es uno de los recursos que acercan el documental de Negroni al de Ruiz Barrachina, en primer lugar porque promueve en el espectador una asociación mental entre la vida, la muerte y la obra de García Lorca al tiempo que subraya la dimensión histórica, cultural e ideológica de ésta y aquéllas; en segundo lugar, porque la decisión de superponer ciertas imágenes a ciertas selecciones textuales lorquianas descontextualizadas viene a sugerir, como tan reiteradamente lo hace Lorca: El mar deja de moverse, una capacidad premonitoria por parte de García Lorca, o por lo menos una cierta dimensión heráldica de su obra7. F.G.L. (1898-1936): Federico cumple 100 años acentúa estas ideas cuando se refiere a la afición del poeta a imaginar su propia muerte y su propio funeral, y también por la prominencia de la muerte en varios de los fragmentos textuales que presenta -partes del "Llanto por Ignacio Sánchez Mejías", uno de los poemas de Suites, el lamento de Bodas de sangre- ya sea mediante lectura en off o mostrando los textos escritos en la pantalla.

El énfasis de los documentales citados en la muerte como elemento clave que imbrica la vida y la obra de García Lorca y que permite entenderlas a ambas desde una perspectiva teleológica y premonitoria es un rasgo que estas y muchas otras producciones comparten con una buena parte de los trabajos críticos sobre el poeta granadino. En relación con éstos, Dinverno ha sugerido que dicho énfasis puede ser evidencia de una "lectura transferencial", término que toma de Dominick LaCapra para proponer que esa pretendida obsesión lorquiana puede ser en buena medida una expresión de la necesidad por parte de los lectores y los críticos de confrontar sus propios conflictos y necesidades en relación con la muerte, la pérdida, la ausencia, el luto (Dinverno, 2005, 46). Dicha idea parece plenamente relevante para tratar de explicar la prominencia de la muerte y su construcción como elemento premonitorio y como anticipación de un destino inevitable que se manifiesta en producciones televisivas y cinematográficas como las que aquí se han referido. Desde tal perspectiva, el protagonismo de la muerte en documentales y filmes de ficción en torno a la figura y la obra de García Lorca sería un testimonio, sobre todo, de las ansiedades culturales de la Andalucia y la España transicionales y democráticas que proveen el contexto en el que las películas y series televisivas se producen, distribuyen y consumen: ansiedades que derivarian, en parte, de las heridas aún abiertas de la guerra civil, de la pervivencia de traumas no confrontados, fantasmas no reconocidos, víctimas ignoradas, historias no contadas, justicia por hacer. $Y$ es precisamente la ausencia del cuerpo de García Lorca, la irresolución de su muerte, lo que convierte a éste y a su obra en un cuerpo/ texto particularmente apto para transferir sobre él todas aquellas ansiedades. La vigencia del mito de García Lorca, fabricado y apuntalado en gran parte por la labor crítica y mediática, dependería pues en gran parte de su capacidad para encarnar ansiedades colectivas, para seguir adoptando significados y usos diversos adecuados a momentos y necesidades culturales variables.

Todas las reflexiones presentadas en este ensayo sobre las recientes representaciones mediáticas de García Lorca -los debates sobre su "andalucidad" o "universalidad"; las diversas mitificaciones y "desmitificaciones" de su figura; los procesos de "somatización" y "textualización" de su obra y su cuerpo; la prominencia de la muerte como clave interpretativa de su vida y su obra; los intereses, necesidades y ansiedades culturales, institucionales e individuales que subyacen a los discursos televisivos y cinematográficos sobre la figura del poeta- confluyen, se diseccionan y se someten a una profunda revisión en el "documental de ficción" El jardín de los poetas, de Basilio Martín Patino. Por ello, parece apropiado dedicar la parte final de este trabajo al análisis de dicho documental.

El jardín de los poetas es uno de los siete capítulos de la serie Andalucía, un siglo de fascinación, dirigida por Basilio Martín Patino, producida por la Linterna Mágica para Canal Sur Televisión y estrenada a finales de 1997. Este capítulo en particular está concebido como una especie de making of que muestra los entresijos del proceso de realización de un supuesto programa de la televisión de Andalucía en homenaje a "los poetas andaluces", en el cual adquiere protagonismo casi absoluto la figura de García Lorca. El documental de ficción de Martín Patino entrelaza imágenes de los técnicos en acción, el montaje

ARBOR Vol. 187748 marzo-abril [2011] 211-222 ISSN: 0210-1963 (1) 
de los escenarios, las negociaciones entre el productor y los patrocinadores, los ensayos, etc., todo lo cual se va intercalando con entrevistas y declaraciones de supuestos "expertos", críticos e historiadores, entre otras personas, así como con fragmentos de presuntos materiales de archivo, supuestos documentos inéditos y otros sorprendentes hallazgos. En conjunto, El jardín de los poetas es tanto una reflexión sobre las recientes representaciones mediáticas de la figura de García Lorca como sobre el contexto cultural, político e ideológico -la Andalucía y la España democráticas, autonómicas, neocapitalistas, ultraconsumistas- en que tales representaciones se han construido, así como una metaexploración sobre el propio medio -la televisión- y género -el documental y sus derivaciones e hibridaciones- desde los que Martín Patino está elaborando su comentario.

Como observa Ana Martín Morán, la elección del término "fascinación" para el título de la serie pone un énfasis explícito en la dimensión subjetiva del proyecto. Los diversos capítulos no tratan de descifrar la "realidad" de la Andalucía del siglo XX, sino de explorar cómo y en torno a qué manifestaciones culturales se han ido construyendo ciertas imágenes de dicha región y cómo se ha fomentado la "fascinación" por ella; a su vez, esa misma exploración está hecha desde una mirada "fascinada" que no se propone ser objetiva ni neutra. En palabras de Martín Morán, "Patino nos ofrece un recorrido por algunas de las ideas clave con las que se ha identificado la identidad andaluza sin evitar el tópico pero poniéndolo en entredicho a través de su peculiar utilización en cada uno de los capítulos" (67). Desde esta perspectiva, el tratamiento irónico del tópico, que combina el reconocimiento y la denuncia de su artificiosidad, parece corresponder precisamente a la elección de un género híbrido, autorreflexivo y metanarrativo como es el documental de ficción, adoptado por Martín Patino en El jardín de los poetas y en el resto de la serie. Al mismo tiempo, en la medida en que Andalucía, un siglo de fascinación es, como indica Martín Morán, un estudio de "los espacios emblemáticos desde donde se ha pensado y recreado la identidad andaluza" (69), parece apropiada la decisión de situar la acción principal de El jardín de los poetas precisamente en un plató de televisión, es decir, un espacio donde la representación, el juego de las apariencias, la realidad y la ficción, la teatralidad, la cultura de masas, los intereses institucionales y financieros, los mitos y ansiedades culturales confluyen literal y figuradamente.
El plató de televisión desde el que se va a retransmitir el programa está instalado en la supuesta Cartuja de CazaIla, en Sierra Morena. Desde ese punto, "en el corazón de Andalucia", se construye y difunde un discurso de "andalucidad" que debe servir como el marco de referencia para interpretar todo el programa y, particularmente, la figura de García Lorca que de él emana. El texto introductorio, que el locutor ensaya repetidamente, denota un tono de celebración andalucista y un mensaje extremadamente similares a los del preámbulo del Estatuto, que se analizó al inicio de este ensayo: "... la cultura cristiana, la musulmana y la hebrea", lee el locutor, "expresión poética de convivencia entre los diversos modos de entender la vida que ha caracterizado siempre la personalidad de Andalucía y su poder de asimilación...." Se trata, pues, de un discurso que subraya la condición multicultural y diversa de la identidad andaluza promovida oficialmente por las instituciones autonómicas. Pero al mismo tiempo que el programa de televisión proclama ese discurso oficialista, el documental inserta comentarios que van estableciendo una distancia irónica y cuestionan las motivaciones, prioridades e intereses de los individuos e instituciones que participan en él. Así, durante un fragmento de la entrevista con un experto que loa la época del califato y El collar de la paloma de Ibn Hazm, la cámara muestra un primer plano del libro de Roger Corman Cómo hice cien films en Hollywood y nunca perdí ni un céntimo. En otro momento, éste de reminiscencias berlanguescas, los patrocinadores del programa -una marca de anis- traen un toro en un remolque junto con unas folclóricas y presionan al productor para que busque el modo de hacerlos aparecer en el programa. Esta imbricación de discurso oficialista, tópicos, estereotipos, oportunismos políticos e intereses comerciales con que $E I$ jardín de los poetas aborda la representación de la identidad andaluza crea el marco -irónico, satírico y críticodesde el cual el documental se aproxima a la vida y obra de García Lorca.

El jardín de los poetas establece una conexión metonímica entre la Cartuja de Cazalla y la figura de García Lorca. El poeta, se nos informa, había estado al menos en dos ocasiones en el hoy abandonado monasterio: una, cuando éste servía como residencia para ciegos en tiempo de la república y García Lorca fue, a iniciativa de las Misiones Pedagógicas, a recitarles sus poemas (lo cual se "documenta" con unas imágenes de un supuesto reportaje de "Cinema Español" titulado La música callada); y otra vez, cuando, 
según la tesis del supuesto experto Benito Cánovas, el poeta estuvo recluido en los días previos a su desaparición, mientras se negociaba su canje por "una importante figura del bando nacional" (quien, de acuerdo a Cánovas, no era otro que José Antonio Primo de Rivera). Mediante recursos como la fabricación de materiales falsos de archivo y la intervención de falsos expertos, el filme de Martín Patino va tejiendo una red de ficciones en torno a Garcia Lorca que se imbrican entre sí y a su vez establecen lazos con elementos de la realidad histórica. A dicha red se añaden, por ejemplo, supuestos fragmentos del No-Do que muestran a las juventudes de la Sección Femenina en la cartuja, convertida en Albergue de Verano, y hasta un supuesto documental sobre los poetas del 27, realizado en 1956 por una tal Angela Wilcox, "poetisa y directora de cine" británica y discípula de Brenan, y en el que aparece, entre otros, Hemingway. Tales elementos contribuyen a articular un cuestionamiento tanto de las nociones de "realidad", "ficción" e "historia" como de las prácticas representacionales mediante las cuales el género documental construye sus discursos y reclama su autoridad testimonial. Parece apropiado que el medio elegido para ello sea precisamente la televisión -por partida doble, ya que El jardín de los poetas es una producción televisiva que a su vez presenta un reportaje sobre un supuesto programa de televisión-. Como señala Jaime Barroso, la televisión ha propiciado desde sus inicios la confusión genérica: "la televisión es un relato, ... una enunciación sin interrupción en la que... clips comerciales, informativos, espacios de ficción narrativa, concursos, magacines, documentales, etc., se suceden sin solución de continuidad; en la que las formas de enlace 0 transición de unos espacios a otros (entre la ficción y la no-ficción) tienden cada vez más a desdibujarse" (Barroso, 2005, 174). Por su parte, Martín Morán describe El jardín de los poetas como un "ejercicio de simulacro... que se transforma en parodia y acaba como un esperpento sobre la capacidad de la televisión de reducir sus objetos hasta hacerlos insignificantes" (72). Y la voz en off del realizador declara en El jardín de los poetas que "todo cuanto toque la televisión tiene que convertirse en barracón circense, que tiene que gustar a millones de espectadores para poder amortizarlo mediante publicidad".

La parodia, el esperpento o el barracón circense de El jardín de los poetas se desarrolla a través de varios procesos que ponen de manifiesto la artificialidad del medio televisivo y, consiguientemente, el carácter de fabricación de los men- sajes que éste produce: El jardín de los poetas es un documental de ficción que se hace pasar por el making of de un supuesto programa de televisión en el que se incorporan fragmentos de supuestos documentales, entrevistas con supuestos expertos que esgrimen supuestos datos y fuentes; lo que se presentará como un programa en vivo está en su mayor parte pregrabado; el público está formado por extras contratados para la ocasión a los que se adiestra acerca de cómo comportarse y cuándo aplaudir; las imágenes de García Lorca y de la poesía, cultura e identidad andaluzas que emanan de dicho programa están a su vez fabricadas y articuladas según la lógica y los intereses del medio televisivo. Subrayando su condición de fabricación y artificiosidad y también su carácter de "barracón circense", el programa incorpora unas marionetas mecánicas articuladas, dirigidas por control remoto, que representan a poetas como el propio Garcia Lorca sentado al piano y a Juan Ramón junto a Platero. Dichas marionetas, descritas por la voz en off del director como "burdas falsificaciones, pastiche viscoso, degradante" y como "figuraciones à la Madame Tussaud", constituyen un comentario muy gráfico sobre la construcción mediática de los mitos y sobre los productos resultantes de tal construcción: en este caso, son productos precarios, de apariencia acartonada, sórdida, inverosímil e inquietante, que además no funcionan y se atascan; el que representa a García Lorca acaba explotando, quemándose y consumiéndose entre la desbandada general que pone fin prematuro al programa.

Con el cortocircuito y consiguiente destrucción de la marioneta de García Lorca culmina toda una serie de tensiones, debates y confrontaciones en torno a la figura del poeta que han ido creciendo en intensidad a lo largo del filme. Inicialmente, el programa de televisión se había planteado como una panorámica sobre la poesía andaluza y debía dar prominencia a los poetas contemporáneos más jóvenes; así lo refleja, por ejemplo, la canción elegida como sintonía del programa, que se escucha en repetidas ocasiones, interpretada por Rosa León y titulada "¿Qué cantan los poetas andaluces de ahora?". Sin embargo, por presiones del productor y los patrocinadores, el realizador ve cómo el protagonismo se va decantando más y más hacia la figura de García Lorca; "hay que darle más énfasis al tema de Lorca, que es el plato fuerte", se oye mientras se ultiman los preparativos para la retransmisión; comentarios similares se reiteran a lo largo del documental. Una escena muestra la agria discusión entre el productor y 
dos invitados, expertos literarios y poetas jóvenes ellos mismos: aquél insiste en que hablen de García Lorca, sobre todo de su muerte, y éstos quieren hablar sobre la joven poesía andaluza contemporánea, que es para lo que se les había convocado. Cuando el documental concluye sin que se haya hablado de los poetas jóvenes ni escuchado uno solo de sus poemas, la canción de Rosa León, que vuelve a sonar, se percibe bajo un prisma irónico y con una sensación de expectativas incumplidas, promesas insatisfechas, preguntas sin resolver.

No hay duda de que El jardín de los poetas se sitúa en un espacio aparte respecto a los demás documentales y películas de ficción que se han mencionado en este ensayo, y no solamente a nivel formal o por su condición de "documental de ficción". Frente a casos como Lorca: el mar deja de moverse o F.G.L. (1898-1936): Federico cumple 100 años, que corroboran imágenes preestablecidas y perpetúan mitos institucionalizados, el filme de Martín Patino pone el énfasis no en la vida ni en la obra de García Lorca sino en los procesos representacionales mediante los que se ha fundamentado el mito lorquiano, los mecanismos retóricos a través de los que se ha construido la "fascinación" colectiva por su figura, y los espacios sociales y culturales desde los que tales iniciativas se han forjado y coordinado durante las últimas décadas. Al mismo tiempo, El jardín de los poetas ofrece una incisiva reflexión sobre los usos del pasado y sobre los efectos que dichos usos tienen sobre el presente. Se trata de una reflexión tan valiente como problemática: a través de recursos como el de las marionetas y de la exploración de las interioridades del medio televisivo, el documental de Martín Patino parece ironizar sobre lo que podría verse como una "inflación" o "hipertrofia" del pasado, un "exceso de pasado" en la cultura española/andaluza contemporánea. Así lo sugeriría la obsesión del productor del programa por otorgar todo el protagonismo a la figura mítica de García Lorca a costa de eclipsar completamente al presente (encarnado en los poetas jóvenes y sus preocupaciones, que aparentemente "no interesan a nadie"). Desde esta perspectiva, el filme de Martín Patino denunciaría, entre otras cosas, la política cultural de la Junta de Andalucía y de la cadena pública Canal Sur Televisión (que irónicamente es la que produce EI jardín de los poetas y también, dentro del mundo ficcional del filme, el programa de televisión). Si el documental de Martín Patino confronta el "exceso de pasado" y la promoción institucional de mitos como el de García Lorca, podría argumentarse que dicho documental acomoda, si no apoya explícitamente, cierto discurso conservador que desde la transición hasta hoy ha venido oponiéndose a la revisitación del pasado, especialmente de la guerra civil y de la represión franquista. Pero hay que notar que lo que EI jardín de los poetas denuncia no es el interés por el pasado en sí, no es la inquietud histórica ni la legitimidad de la construcción de una memoria cultural sino la trivialización y explotación de mitos prefabricados, de tópicos tan

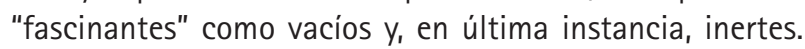
Puede entenderse, entonces, que es el mito acartonado, hipergastado por el abuso, de García Lorca lo que Martín Patino hace estallar al final de su película, y que son sus promotores institucionales y financieros quienes se convierten en pasto de las llamas: final apocalíptico cuya retransmisión constituye, por cierto, un espectáculo televisivo de primera magnitud.

\section{NOTAS}

1 Véanse los libros y artículos de C. B. Morris, María Teresa García-Abad, Rafael Utrera, Antonio Monegal, Uta Felten, y Vicente Molina-Foix, entre otros.

2 Zorongo y Lorca, Santiago y seis poemas gallegos son montajes audiovisuales sobre textos de poemas de

Recibido: 14 de octubre de 2008

Aceptado: 3 de marzo de 2009
García Lorca; sin ser representaciones explícitas de la figura del poeta ni tampoco adaptaciones propiamente dichas, tales producciones permiten detectar determinados procesos de construcción de una cierta imagen del poeta a través de la elección de textos, música, fotografía y estilo de montaje, por ejemplo. En una categoria aparte estarian filmes como $E$ I crimen de una novia (Lola Guerrero, 2006) -pseudo-documental que traza la investigación del suceso real en el que se inspiró García Lorca para 
escribir Bodas de sangre-, y el documental Verbotene Früchte (Fruta prohibida), de la televisión alemana (2002), sobre los entresijos de una representación de La casa de Bernarda Alba en Teherán. A todas las producciones televisivas y cinematográficas citadas habría que añadir las numerosas adaptaciones de dramas lorquianos que se realizan sobre todo a partir de los años 70.

3 Queda para otra ocasión el análisis de la serie Buscando a Lorca, producida por Canal Sur TV, cuyas perspectivas son, sin duda, muy reveladoras en el contexto de esta discusión.

4 El título El balcón abierto es una referencia al poema "Despedida", del libro Canciones. El mar deja de moverse es una referencia al poema "Asesinato", de Poeta en Nueva York. Ambos textos se refieren a la muerte.

5 La luz prodigiosa de Miguel Hermoso también se inicia con el fusilamiento aunque en dicha película Garcia Lorca sobrevive a los disparos.

6 Del Libro de poemas, primer libro de poemas de García Lorca.

7 Resulta interesante que la cita de Bodas de sangre se interrumpa en el punto en que lo hace, puesto que es justamente en las líneas que siguen cuando el texto lorquiano es más evocador en relación con el fin del propio García Lorca: "Pero no; camposanto no, camposanto no; lecho de tierra, cama que los cobija y que los mece por el cielo" (García Lorca, Bodas de sangre, 161).

\section{BIBLIOGRAFÍA}

Assassinio de Federico Garcia Lorca (1976): Dir. Alessandro Cane.

A un dios desconocido (1977): Dir. Jaime Chávarri.
El balcón abierto (1984): Dir. Jaime Camino.

Albert, Mechthild (ed.) (2005): Vanguardia española e intermedialidad: artes escénicas, cine, radio. Madrid, Iberoamericana.

Barroso, Jaime (2005): "Docudrama y otras formas en el límite de la ficción televisiva española" en María Luisa Ortega (coord.), pp. 171-206.

Buscando a Lorca (1998): Dir. María Luisa Chamorro y Jesús Vigorra.

Constitución Española. http://constitucion. rediris.es/legis/1978/ce1978.html.

El crimen de una novia (2006): Dir. Lola Guerrero.

Deep Song, Black Sound (1968).

Dinverno, Melissa (2005): "Raising the Dead: Garcia Lorca, Trauma, and the Cultural Mediation of Mourning", Arizona Journal of Hispanic Cultural Studies, 9, pp. 29-52.

- (2007): "Wounded Bodies: García Lorca, Memory, and the Ghostly Return of the Past in Miguel Hermoso's La luz prodigiosa", Anales de la literatura española contemporánea, 32.1, pp. 5-36.

Estatuto de Autonomía de Andalucía. http://www.andaluciajunta.es/especiales/aj-nuevoestatuto-estatuto. html?idSeccion=1\&idApartado=1.

Federico García Lorca: Murder in Granada (1976): Dir. Humberto López y Guerra.

Federico García Lorca: Retrato de familia (1998): Dir. Enrique Nicanor.

Felten, Uta (2005): "El cine como generador de la escritura vanguardista en Federico García Lorca", en Mechthild Albert (ed.), pp. 479-88.

F.G.L. (1898-1936): Federico cumple 100 años (1998): Dir. Magali Negroni.

García, A. Víctor: "El año dedicado a Federico García Lorca nace para desmitificar la vida y la obra del poeta http://www.elpais.com/articulo/cultura/ano/dedicado/Federico/Garcia/Lorca/nace/desmitificar/vida/obra/poeta/ elpepicul/19860105elpepicul_3/Tes.
García-Abad García, María Teresa (2005): Intermedios: estudios sobre literatura, teatro y cine, Madrid, Fundamentos.

- (2001): "Una Bernarda de cine: Lorca del papel a la pantalla", Estreno 27.2, pp. 4-7.

García Lorca, Federico (1990): Bodas de sangre, Madrid, Cátedra.

- (1986): Canciones, Madrid, EspasaCalpe.

- (1961): Libro de poemas, Buenos Aires, Losada.

- (1972): Poeta en Nueva Cork, Madrid, Espasa-Calpe.

Gibson, Ian. The Assassination of Federico García Lorca. Londres: W. H. Allen, 1979.

La Granada de García Lorca. Episodio de la serie de TVE La víspera de nuestro tiempo (1968): Dir. Jesús Fernández Santos.

El jardín de los poetas (1995): Dir. Basilio Martín Patino.

Little Ashes (2009): Dir. Paul Morrison.

Lorca, asi que pasen cien años (1998): Dirs. José Luis López Linares y Javier Royo. Lorca, centenario de un poeta (1998).

Lorca, el mar deja de moverse (2006): Dir. Emilio Ruiz Barrachina.

Lorca, muerte de un poeta (1986): Dir. Juan Antonio Bardem.

Lorca, Santiago y seis poemas gallegos (1999): Dir. Alber Ponte.

La luz prodigiosa (2003): Dir. Miguel Hermoso.

Martín Morán, Ana (2005): "La inocencia subversiva: pistas falsas y alguna certeza sobre la producción audiovisual de Basilio Martín Patino", en María Luisa Ortega (coord.), pp. 47-82.

Molina Foix, Vicente (1999): "98 y 27: dos generaciones ante el cine (Baroja y Lorca como guionistas)", Bulletin of Spanish Studies 76.1, pp. 157-71.

Monegal, Antonio (ed.) (1994): Viaje a la luna (guión cinematográfico) de Federico García Lorca, Valencia, Pre-Textos.

Morris, C. B. (1980): This Loving Darkness: The Cinema and Spanish Writers, 
1920-1936. Oxford, UK, Oxford University Press.

Muerte en Granada (The Disappearance of Garcia Lorca) (1997): Dir. Marcos Zurinaga.

Ortega, María Luisa (coord.) (2005): Nada es lo que parece: falsos documentales, hibridaciones y mestizajes del documental en España, Madrid, Ocho y Medio.
Schreckenberg, Stefan (2006): "La conmemoración del Centenario de García Lorca como contribución a la memoria cultural de España: dos documentales de TVE y Canal+", en Ulrich Winter (ed.), pp. 223-37.

Utrera, Rafael (1982): García Lorca y el cinema, Sevilla, Edisur.

Verbotene Früchte (2002): Dir. Peter Kreysler.
Vila-San Juan, José Luis (1975): García Lorca, asesinado: toda la verdad, Barcelona, Planeta.

Winter, Ulrich (ed.) (2006): Lugares de memoria de la guerra civil y el franquismo: representaciones literarias y visuales, Madrid, Iberoamericana.

Zorongo (Recordando a García Lorca). Dir. Eugenio Pena, 1969. 